\title{
The coincidence of necrotizing enterocolitis and rotavirus infections and potential associations with cytokines
}

\author{
Efsun Sızmaz $M D^{1}$, Mehmet Satar $M D^{2}$, Ferda Özlü $M D^{2}$, Akgün Yaman $M D^{3}$, \\ Hacer Yapıcıoğlu Yıldızdaş MD², Kenan Özcan MD²
}

E Sızmaz, M Satar, F Özlü, A Yaman, HY Yıldızdaş, K Özcan. The coincidence of necrotizing enterocolitis and rotavirus infections and potential associations with cytokines. Can J Infect Dis Med Microbiol 2012;23(4):e103-e105.

BACKGROUND: Necrotizing enterocolitis (NEC) is the most common gastrointestinal disease in neonatal intensive care units. Although the pathogenesis of NEC remains unclear, evidence suggests that infections, especially bacterial infections, may play an important role. Viral infections may also result in NEC. Several outbreaks of NEC associated with rotaviruses have been described previously.

OBJECTIVE: To investigate the association between rotavirus (RV) and serum interleukin (IL)- 6 and IL-8 levels in infants with NEC.

METHODS: RV infections were prospectively studied using antigen detection in the stools of 31 infants with NEC. Additionally, serum levels of IL-6, IL-8 and tumour necrosis factor-alpha were tested using micro-ELISA at $\mathrm{O}$ h and $48 \mathrm{~h}$ after diagnosis of NEC.

RESULTS: Fecal specimens from 13 infants were positive, while fecal specimens from 18 infants were negative for RV according to antigen detection (RV+ and RV- groups, respectively). The mortality rate and the severity of NEC were not significantly different between the RV+ and RV- groups. IL-6 levels at $\mathrm{O}$ and $48 \mathrm{~h}$ after diagnosis of NEC in $\mathrm{RV}+$ infants were lower compared with RV- infants, while IL-8 levels were greater at $\mathrm{Oh}$ and $48 \mathrm{~h}$ after diagnosis of NEC in RV+ infants compared with RV- infants.

CONCLUSION: A high prevalence of RV infection in neonates with NEC was found. Decreased IL-6 levels and increased IL-8 and tumour necrosis factor-alpha levels in RV+ neonates with NEC suggests a role for RV in NEC.

\section{Key Words: Cytokines; Necrotizing enterocolitis; Rotavirus}

Tecrotizing enterocolitis (NEC) is a disease that predominantly 1 affects premature infants. It is the most common gastrointestinal disease in neonatal intensive care units (NICUs). Although the pathogenesis of NEC remains unclear, infections by bacteria and viruses may play an important causative role (1-4).

Several outbreaks of NEC associated with rotaviruses have been described previously $(5,6)$. Rotaviruses are found throughout the world and generally affect children younger than four years of age. Most rotavirus infections are community acquired, but some infections may be acquired at health care facilitites. There are some reports of rotavirus outbreaks in pediatric wards and neonatal units $(7,8)$. Infections in neonates can be asymptomatic or mild and, therefore, may sometimes go undetected.

The pathophysiology of NEC has been difficult to ascertain, but accumulating evidence suggests that an imbalance between an activated proinflammatory response and an inadequate anti-inflammatory protective response results in the hallmark findings of intestinal necrosis and NEC. In clinical studies measuring systemic activation of the inflammatory response, samples from NEC patients showed elevated levels of various inflammatory mediators compared with gestational agematched controls (9). Thrombocyte activating factor, tumour necrosis

\section{La coïncidence de l'entérocolite nécrosante et des infections à rotavirus et leurs associations potentielles avec les cytokines}

HISTORIQUE : L'entérocolite nécrosante (ECN) est la principale maladie gastro-intestinale observée dans les unités de soins intensifs néonatals. Même si la pathogenèse de l'ECN demeure nébuleuse, les données probantes indiquent que les infections, notamment les infections bactériennes, peuvent y jouer un rôle important. Les infections virales peuvent également provoquer une ECN. Plusieurs éclosions d'ECN associées à des rotavirus ont été décrites par le passé.

OBJECTIF : Explorer l'association entre le rotavirus (RV) et les taux d'interleukine sérique (IL)-6 et IL-8 chez les nourrissons ayant une ECN. MÉTHODOLOGIE : Les chercheurs ont étudié les infections à RV de manière prospective au moyen de la détection des antigènes dans les selles de 31 nourrissons atteints d'une ECN. Ils ont également testé les taux sériques d'IL-6, d'IL-8 et de facteur de nécrose tumorale alpha au moyen du test microELISA immédiatement après le diagnostic d'ECN, puis 48 heures plus tard. RÉSULTATS : Les échantillons fécaux de 13 nourrissons étaient positifs, tandis que ceux de 18 nourrissons étaient négatifs au RV d'après la détection des antigènes (groupe $\mathrm{RV}+$ et groupe $\mathrm{RV}-$, respectivement). Le taux de mortalité et la gravité de l'ECN ne différaient pas de manière significative entre le groupe RV+ et le groupe RV-. Les taux d'IL-6 immédiatement après le diagnostic d'ECN et 48 heures plus tard chez les nourrissons du groupe RV+ étaient inférieurs à ceux des nourrissons du groupe $\mathrm{RV}-$, tandis que les taux d'IL-8 étaient plus élevés immédiatement après le diagnostic d'ECN et 48 heures plus tard chez les nourrissons du groupe RV+ que chez ceux du groupe RV-.

CONCLUSION : Les chercheurs ont décelé une forte prévalence d'infection à RV chez les nouveau-nés ayant une ECN. Les taux d'IL-6 moins élevés et d'IL-8 et de facteur de nécrose tumorale alpha plus élevés chez les nouveau-nés du groupe RV+ ayant une ECN laissent supposer que le RV joue un rôle dans l'ECN.

factor (TNF)-alpha and interleukins (ILs)(IL-1, IL-6, IL-8, IL-10, IL-12 and IL-18) are some of the inflammatory mediators that have a role in the pathogenesis of NEC (4).

The aim of the present study was to investigate the prevalence of rotavirus infection and the potential role of specific ILs in the clinical progress of infants with NEC.

\section{METHODS}

The present study was prospectively designed and included NICU patients seen between May 1, 2007 and November 30, 2009. All patients with NEC $(n=31)$ were included in the study. The study protocol was approved by the university's ethics committee.

NEC was staged according to the modified Bell's criteria (10). A single radiologist examined all radiographs.

Infants with NEC and stool specimens positive for rotavirus antigen formed one group $(\mathrm{NEC} \mathrm{RV+)}$ ) and infants with NEC without rotavirus antigen in their stool specimen (NEC RV-) formed the other group.

Demographic factors were also recorded, including route of delivery, birth weight, sex, Apgar scores $1 \mathrm{~min}$ and $5 \mathrm{~min}$ after delivery, and intrauterine growth patterns. Standard laboratory tests, including complete blood count, blood gas analysis, serum biochemistry 


\begin{tabular}{|c|c|}
\hline$(n=31)$ & \\
\hline Male/female, $n / n$ & $21 / 10$ \\
\hline AGA/SGA, $n / n$ & $23 / 8$ \\
\hline Cesarean section/NVD, n/n & 20/11 \\
\hline Gestational age, weeks & $30.6 \pm 3.5$ \\
\hline Birth weight, $\mathrm{g}$ & $1492.4 \pm 647.8$ \\
\hline Postnatal age at onset of NEC, days & $11.8 \pm 7.8$ \\
\hline Infants on ventilatory support, $\mathrm{n}$ & 24 \\
\hline Time on ventilatory support, days & $13.5 \pm 16.1$ \\
\hline \multicolumn{2}{|c|}{$\begin{array}{l}\text { Data presented as mean } \pm S D \text { unless otherwise indicated. AGA Appropriate } \\
\text { for gestational age; NVD Normal vaginal delivery; SGA Small for gestationa } \\
\text { age }\end{array}$} \\
\hline \multicolumn{2}{|c|}{$\begin{array}{l}\text { TABLE } 2 \\
\text { Clinical findings of infants with necrotizing enterocolitis } \\
(n=31)\end{array}$} \\
\hline Finding & $\mathrm{n}(\%)$ \\
\hline Thrombocytopenia & $18(58)$ \\
\hline Leukopenia & $12(38.7)$ \\
\hline Metabolic acidosis & $27(87)$ \\
\hline Hyperkalemia & $13(41.9)$ \\
\hline Positive blood culture & $25(80)$ \\
\hline Positive guaiac test & $30(96.8)$ \\
\hline
\end{tabular}

and blood cultures were performed. In addition, feeding patterns and therapeutic interventions were also examined.

Fecal specimens were collected in the first $24 \mathrm{~h}$ following diagnosis of NEC and tested for rotavirus according to the latex agglutination method (Omega, United Kingdom). Serum levels of IL-6, IL-8 and TNF-alpha were tested by micro-ELISA (Biosource Europa SA, Belgium) using the Grifols Triturus automation system (Grifols, Spain) at $\mathrm{O}$ and $48 \mathrm{~h}$ following the diagnosis of NEC.

Thrombocytopenia was defined as a platelet count $<100 \times 10^{9} / \mathrm{L}$, leukopenia was defined as a white blood cell count $<5 \times 10^{9} / \mathrm{L}$ and hyperkalemia was defined as a serum potassium level $>6 \mathrm{mmol} / \mathrm{L}$.

Statistical analysis was performed using SPSS version 17.0 (IBM Corporation, USA) for Windows (Microsoft Corporation, USA). NEC $\mathrm{RV}+$ and NEC RV - infants were compared using the $\chi^{2}$ test for dichotomous variables. Group comparisons of these variables were performed using the $t$ test for normally distributed and the Mann-Whitney test for non-normally distributed variables. Variables found to be statistically significant in the univariate analysis were used in the multivariate logistic regression analysis; $\mathrm{P} \leq 0.05$ was considered to be statistically significant.

\section{RESULTS}

Thirty-one infants (21 male, 10 female) were diagnosed with NEC. Demographic data including mode of delivery, sex, gestational age, birth weight, growth according to gestational age and duration of ventilatory support are shown in Table 1.

According to the modified Bell's criteria for NEC staging, $11(35.5 \%)$ of the infants were stage I, $17(54.8 \%)$ were stage II and three $(9.7 \%)$ were stage III. Twenty-four infants were on mechanical ventilatory support for a mean $( \pm$ SD) duration of $13.5 \pm 16.1$ days. Laboratory data are shown in Table 2.

The fecal specimens for 13 (41.9\%) of the infants were positive for rotavirus and formed the NEC RV+ group, while the fecal specimens for the remaining 18 (58.1\%) infants were negative for rotavirus and formed the NEC RV- group. Due to the seasonal variation of rotavirus, six $(46.2 \%)$ of the infants had infection in the spring and two $(15.4 \%)$ had infection in the summer. Although the rate of infection in summer and spring was higher compared with winter and autumn, this was not statistically different $(\mathrm{P}=0.657)$. Rotavirus infection was higher in infants who were small for their gestational age $(52.2 \%)$
TABLE 3

Cytokine levels of infants with necrotizing enterocolitis $(n=31)$

\begin{tabular}{llccc}
\hline Cytokine & \multicolumn{1}{c}{ Rotavirus+ $(\mathbf{n}=13)$} & Rotavirus $-(\mathbf{n}=18)$ & $\mathbf{P}$ \\
\hline IL-6, pg/mL & $0 \mathrm{~h}$ & $124 \pm 195.9(3-700)$ & $338.9 \pm 958.6(0-4000)$ & 0.609 \\
& $48 \mathrm{~h}$ & $46.1 \pm 67.3(0-200)$ & $252.2 \pm 783.5(0-3825)$ & 0.017 \\
$\mathrm{IL}-8, \mathrm{pg} / \mathrm{mL}$ & $0 \mathrm{~h}$ & $1921.2 \pm 2321.8(9-7092)$ & $965.2 \pm 1691.4(10-5290)$ & 0.070 \\
& $48 \mathrm{~h}$ & $1512.4 \pm 1999.6(0-5900)$ & $570.3 \pm 1186.4(6-4300)$ & 0.017 \\
TNF-alpha, & $0 \mathrm{~h}$ & $31.4 \pm 72.0(1-430)$ & $12.3 \pm 18.0(0-97)$ & 0.352 \\
$\mathrm{pg} / \mathrm{mL}$ & & & & \\
& $48 \mathrm{~h}$ & $30.8 \pm 10.7(1-280)$ & $13.5 \pm 18.5(0-97)$ & 0.880
\end{tabular}

Data presented as mean $\pm S D$ (range). IL Interleukin; TNF Tumour necrosis factor; - Negative; + Positive

compared with infants who were of appropriate size and wieght (12.5\%) $(\mathrm{P}=0.037)$.

Six of $16(37.5 \%)$ breastfed infants and five of 12 (41.6\%) formulafed infants were RV+. Rotavirus infection was lower in breastfed than in formula-fed infants but this difference was not statistically significant.

The duration of hospitalization was $49.3 \pm 29.9$ days for NEC RV+ infants and $30 \pm 24.7$ days in NEC RV- infants. Although rotavirus infection increased the duration of hospitalization, this difference was not statistically significant. Ten infants died $(32.3 \%)$, three of whom were $\mathrm{RV}+$ and seven of whom were RV-. The mortality rate was lower in $\mathrm{RV}+$ infants, but this difference was not statistically significant $(\mathrm{P}=0.452)$. In the NEC RV+ group, $38.5 \%$ of infants were stage I, $53.8 \%$ of infants were stage II and $7.7 \%$ of infants were stage III. In the NEC RV - group, $33.3 \%$ of infants were stage I, 55.6\% of infants were stage II and $11.1 \%$ of infants were stage three. The rate of stage II NEC was higher in both NEC RV+ and NEC RV- infants, but this was not statistically different.

IL-6, IL-8 and TNF-alpha levels at $0 \mathrm{~h}$ and $48 \mathrm{~h}$ after diagnosis of $\mathrm{NEC}$ are shown in Table 3. IL-6 levels in NEC RV+ infants at $\mathrm{O}$ and $48 \mathrm{~h}$ after diagnosis of NEC were lower than in NEC RV- infants (for $0 \mathrm{~h} \mathrm{P}=0.609$ and for $48 \mathrm{~h} \mathrm{P}=0.017$ ), but only the difference in levels after $48 \mathrm{~h}$ was statistically significant. IL-8 levels in NEC RV+ infants at $\mathrm{O}$ and $48 \mathrm{~h}$ after diagnosis were higher than NEC RV - infants and the differences in levels were statistically significant $(P=0.007$ and $\mathrm{P}=0.004$, respectively). TNF-alpha levels in NEC RV+ infants at $0 \mathrm{~h}$ and $48 \mathrm{~h}$ after diagnosis of NEC were slightly higher than NEC RVinfants. However, the differences in the levels of TNF-alpha were not statistically significant $(\mathrm{P}=0.352$ and $\mathrm{P}=0.880$, respectively).

\section{DISCUSSION}

In the present study, the prevalence of rotavirus infection and its association with ILs in infants with NEC was evaluated. In the present study, stage II NEC was the most common and stage III was the least common. Sharma et al (11) reported that the majority of the infants with NEC were in stage II or III, according to the modified Bell's criteria.

Although newborn infants have an immature immune system, neonatal rotavirus infections and gastroenteritis are uncommon due to maternal antibodies and the protective effect of human milk; however, because premature infants lack these protective antibodies, they are at higher risk for rotavirus infections in neonatal wards. Most of our patients are premature infants. The role of rotavirus in the pathogenesis of NEC has not been established. Previous authors have suggested that a possible synergism between rotavirus and other microorganisms can worsen the infection in the intestine and cause NEC (12). Nosocomial and community-acquired rotavirus gastroenteritis is frequent in winter and early spring. The present study found that the stool from infants with NEC was positive for the rotavirus antigen in $41.9 \%$ of cases. The presence of rotavirus in stool samples collected in spring and summer is higher than in stool samples collected in winter and autumn. This may be associated with the higher incidence of NEC in summer and spring in the present study.

In a retrospective analysis, Keller et al (13) compared NEC RV+ and NEC RV- patients reported that rotavirus infections were more 
common in mature infants. In contrast, in the present study, NEC $\mathrm{RV}+$ was more common in premature infants, which may be related to the differences in the populations or the different methods used to detect rotavirus in stool. Brufau et al (14) reported that NEC RV+ was significantly more common in low-weight infants; this trend was also confirmed by the present study.

Sharma et al (11) indicated that rotavirus infection does not increase the risk of developing advanced NEC. Of the 13 infants infected with rotavirus, 38.5\% had Bell's stage I, 53.8\% had Bell's stage II and 7.7\% had Bell's stage III NEC. The percentage of patients in different NEC stages were similar in RV- and RV+ infants. However, the present study demonstrates that rotavirus infection lengthens hospital stay in infants with NEC.

Thrombocyte activating factor, TNF-alpha and ILs (IL-1, IL-6, IL-8, IL-10, IL-12 and IL-18) are believed to play a role in the pathogenesis of NEC. IL-6 is a sensitive marker ( $87 \%$ sensitivity, $93 \%$ to $100 \%$ negative predictive value) in the diagnosis of early neonatal sepsis following invasion of bacteria (14). IL-6 levels are higher in infants with NEC and/or sepsis than in uninfected infants $(15,16)$. Caplan et al (9) studied 12 infants with NEC and reported that IL-6 levels were 10 times higher in infants with sepsis and was a marker of mortality. Romagnoli et al (17) reported that IL-6, IL-10 and C-reactive protein levels were higher in infants with sepsis, pneumonia and NEC. The higher sensitivity of these cytokines exhibited at the beginning of an infection declines over time ( $89 \%$ at $0 \mathrm{~h}, 67 \%$ at $24 \mathrm{~h}$ and $58 \%$ at $48 \mathrm{~h}$ of infection) (17).

In the present study, IL- 6 levels were lower at $0 \mathrm{~h}$ and $48 \mathrm{~h}$ in NEC $\mathrm{RV}+$ infants compared with NEC RV- infants. Due to the shorter half-life of IL-6, after 24 h of treatment IL-6 levels can decrease and could not be detected in the NEC RV+ infants. Alternatively, there may also be other causative microbial agents playing a role in NEC in NEC RV - infants.

Increased levels of IL-8 in infants with NEC and its relation to disease severity have been reported in many studies $(15,18)$. Harris et al (16) compared infants with stage III NEC and imperforated anus with healthy controls and reported an increase in the levels of IL-6 and IL-8 in the NEC group. Xu et al (19) reported significantly elevated IL-8 and some other cytokine levels, detected by ELISA, in rotavirus-infected

\section{REFERENCES}

1. Uauy R, Fanarof AA, Korones S, et al. Necrotizing enterocolitis in a very low birth weight infants: Biodemographic and clinical correlates. J Pediatr 1991;119:630-8.

2. Hack M, Horbar JD, Malloy MH, et al. Very low birth weight outcomes of the National Institute of Child Health and Human Development Neonatal Network. Pediatrics 1991;87:587-97.

3. Hsueh W, Caplan MS, Qu XW, et al. Neonatal necrotizing enterocolitis: Clinical considerations and pathogenetic concepts. Pediatr Dev Pathol 2003;6:6-23.

4. Guthrie SO, Gordon PV, Thomas V, et al. Necrotizing enterocolitis among neonates in the United States. J Perinatol 2003;23:278-85.

5. Sharma R, Garrison RD, Tepas JJ III, et al. Rotavirus-associated necrotizing enterocolitis: An insight into a potentially preventable disease? J Pediatr Surg 2004;39:453-7.

6. Rotbart HA, Levin MJ, Yolken RH, et al. An outbreak of rotavirusassociated neonatal necrotizing enterocolitis. J Pediatr 1983;103:454-9.

7. Herruzo R, Omeñaca F, García S, et al. Identification of risk factors associated with nosocomial infection by rotavirus $\mathrm{P} 4 \mathrm{G} 2$, in a neonatal unit of a tertiary-care hospital. Clin Microbiol Infect 2009; $15: 280-5$.

8. Chandran A, Heinzen RR, Santosham M, et al. Nosocomial rotavirus infections: A systematic review. J Pediatr 2006;149:441-7.

9. Caplan MS, Sun XM, Hseuh W, et al. Role of platelet activating factor and tumor necrosis factor-alpha in neonatal necrotizing enterocolitis. J Pediatr 1990;116:960-4.

10. Ballard JL, Khoury JC, Wedig K, et al. New Ballard Score, expanded to include extremely premature infants. J Pediatr 1991;119:417-23. intestinal epithelial cells at $24 \mathrm{~h}$ to $48 \mathrm{~h}$ postinfection. The present study found that IL-8 levels in NEC RV+ infants at $0 \mathrm{~h}$ and $48 \mathrm{~h}$ of disease were statistically higher than in NEC RV- infants.

Elevated plasma TNF-alpha levels have been detected in infants with NEC. In addition, elevated IL-1, TNF-alpha as well as IL-6 levels have been found in the ascites fluid of neonates treated for NEC. At the tissue level, increased IL-1 and TNF-alpha messenger RNA levels have been detected in resected bowel specimens of infants with NEC. At the time of surgical reanastomosis, these cytokine levels were markedly decreased (20). Also in the present study, TNF-alpha levels at $\mathrm{O} \mathrm{h}$ and $48 \mathrm{~h}$ in NEC RV+ infants were higher than in NEC RV- infants.

Sharma et al (11) reported that pneumatosis intestinalis of varying severity was present in all NEC RV+ infants. This was not confirmed by our investigation. Of the seven infants with pneumatosis intestinalis, two $(28.6 \%)$ had rotavirus infection. Rotavirus infection did not have any effect on the development of pneumotosis intestinalis. Of the 31 infants with NEC, 10 (32.3\%) died and, of these 10, three had rotavirus in their stool specimen while seven did not.

The present study has some limitations. The genotypes of the rotavirus found in stool specimens of NEC+RV patients could have been determined. Also, all of the patients that were hospitalized during the study period could have had their stool specimens tested for rotavirus antigen.

\section{CONCLUSION}

The aim of the present study was to investigate the prevalence of rotavirus infection and the association of cytokines, such as IL-6, IL-8 and TNF-alpha, with rotavirus infection in neonates with NEC. We found a high rotavirus infection rate in neonates with NEC. In addition, decreased IL-6 levels and increased IL-8 and TNF-alpha levels in NEC $\mathrm{RV}+$ infants indicate a possible role for rotavirus in NEC.

NEC is an important cause of neonatal mortality and morbidity. Prevention of rotavirus infections may not only decrease the incidence of NEC but may also decrease mortality and morbidity in the neonatal period.

To demonstrate whether NEC RV- is different from NEC RV+ and to confirm that rotavirus plays a role in the causation of NEC, more multicentre studies with larger sample sizes are necessary.

11. Sharma R, Hudak ML, Premachandra BR, et al. Clinical manifestations of rotavirus infection in the neonatal intensive care unit. Pediatr Infect Dis J 2002;21:1099-105.

12. Bagci S, Eis-Hübinger AM, Yassin AF, et al. Clinical characteristics of viral intestinal infection in preterm and term neonates. Eur J Clin Microbiol Infect Dis 2010;29:1079-84.

13. Keller KM, Schmidt H, Wirth S, et al. Differences in the clinical and radiologic patterns of rotavirus and non-rotavirus necrotizing entrocolitis. Pediatr Infect Dis J 1991;10:734-738.

14. Brufau AR, Romero MV, Ubieto PM, et al. Epidemic neonatal necrotizing enterocolitis, associated with rotavirus gastroenteritis. Ann Esp Pediatr 1988;29:307-310.

15. Procianoy RS, Silveira RC. The role of sample collection timing on interleukin-6 levels in early-onset neonatal sepsis. J Pediatr 2004;80:407-10.

16. Harris MC, Costarino AT Jr, Sullivan JS, et al. Cytokine elevations in critically ill infants with sepsis and necrotizing enterocolitis. J Pediatr 1994;124:105-11.

17. Romagnoli C, Frezza S, Cingolani A, et al. Plasma levels of interleukin- 6 and interleukin-10 in preterm neonates evaluated for sepsis. Eur J Pediatr 2001;160:345-50.

18. Lin PW, Stoll BJ. Necrotising enterocolitis. Lancet 2006;368:1271-83

19. Xu J, Yang Y, Wang C, et al. Rotavirus and coxsackievirus infection activated different profiles of toll-like receptors and chemokines in intestinal epithelial cells. Inflamm Res 2009;58:585-92.

20. Martin CR, Walker WA. Intestinal immune defences and the inflammatory response in necrotising enterocolitis. Semin Fetal Neonatal Med 2006;11:369-77. 


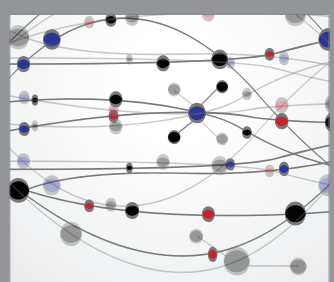

The Scientific World Journal
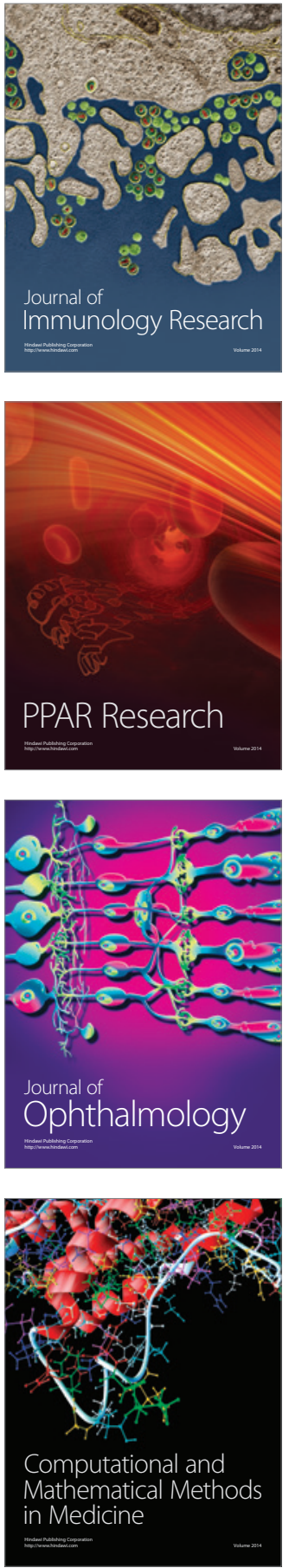

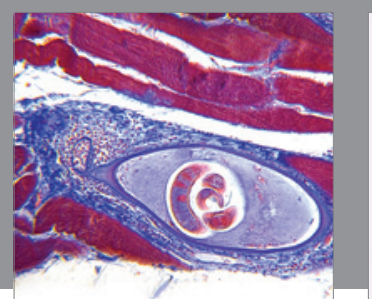

Gastroenterology Research and Practice

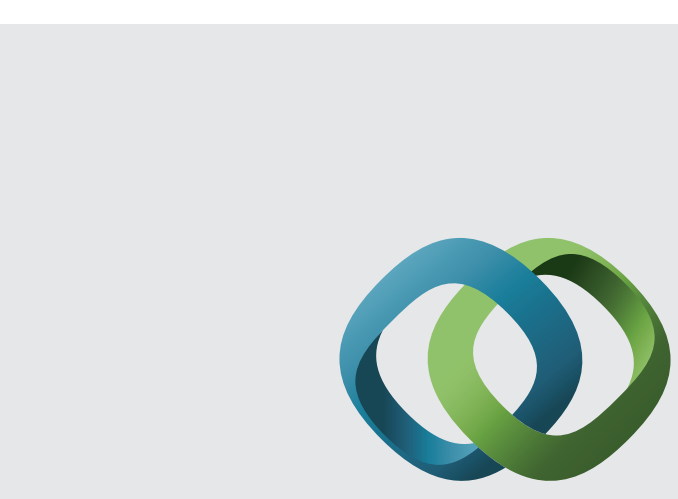

\section{Hindawi}

Submit your manuscripts at

http://www.hindawi.com
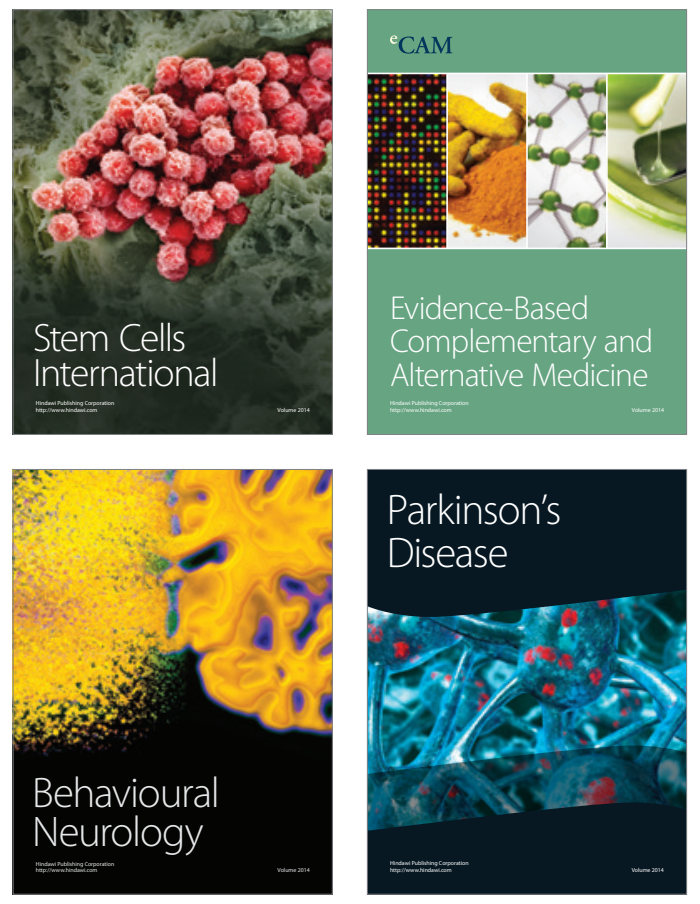
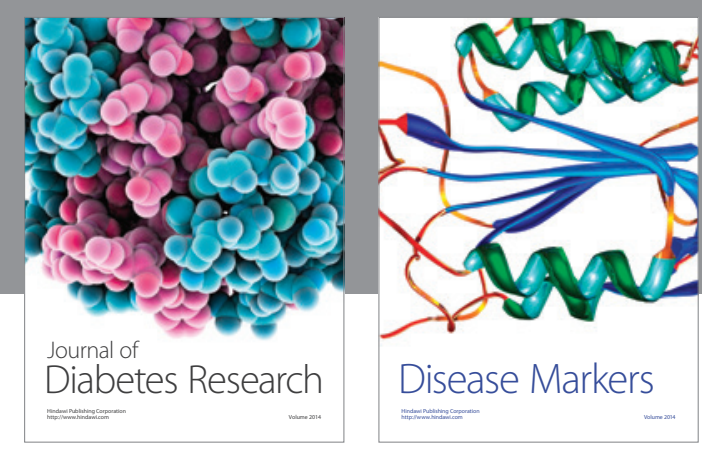

Disease Markers
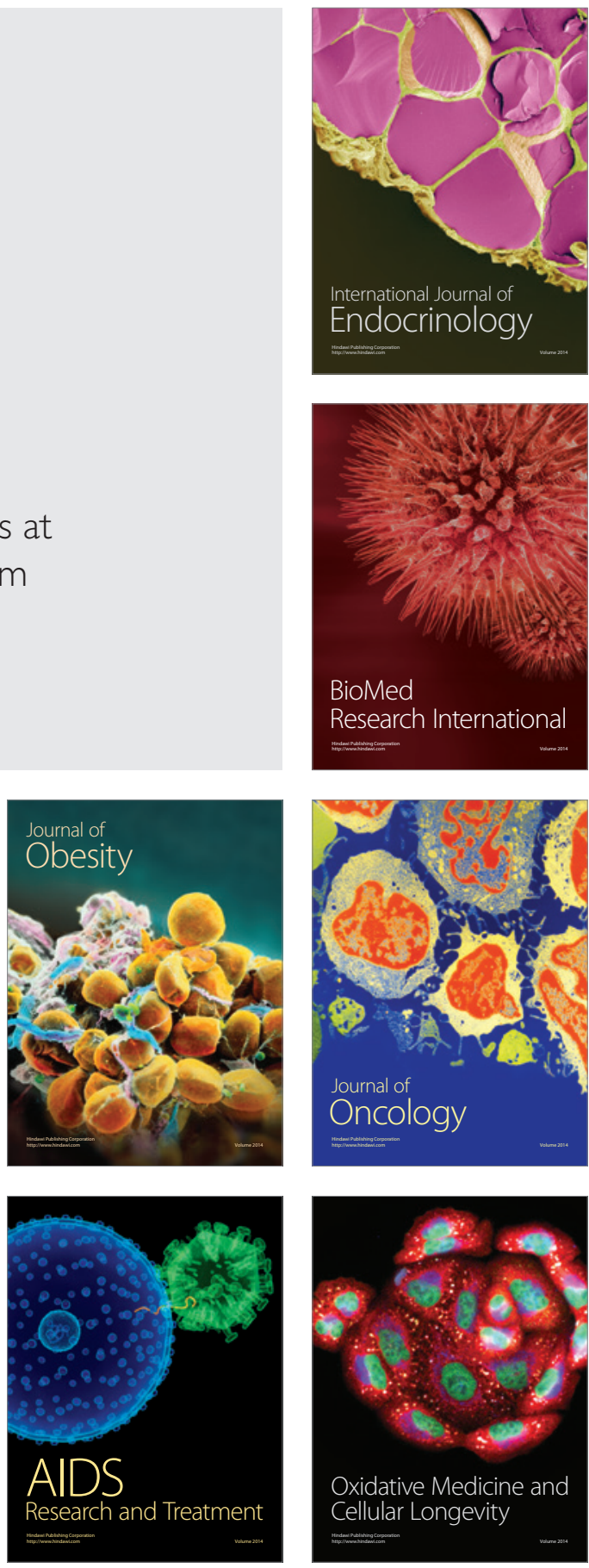